\title{
Strategi Dinas Perpustakaan dan Arsip Daerah (DPAD) Provinsi Jambi dalam Mengembangkan Perpustakaan Berbasis Inklusi Sosial untuk Mewujudkan Masyarakat Literate
}

\author{
${ }^{1}$ Khairunisa, Wenny Dastina ${ }^{2}$, Buchari Katutu ${ }^{3}$ \\ Universitas Islam Negeri Sultan Thaha Saifuddin Jambi \\ Jalan Jambi- Muaro Bulian Km.16, Muaro Jambi, 36363 \\ e-mail: khairunisaprwra@gmail.com
}

\begin{abstract}
Introduction. The purpose of this study was to determine the Jambi Province DPAD Strategy in developing a Social Inclusion-Based Library to Create a Literate Society, constraining factors in developing a social inclusion-based library in an effort to create a literate community in the Jambi Province Regional Library and Archives Service, and the efforts made to overcome these obstacles.

Data Collection Metod. This study used a descriptive qualitative method with a purposive sampling approach.

Resilt and Discussions. The results of this study indicate that there are several strategies implemented by DPAD Jambi Province in developing social inclusion in libraries, namely: involving the active role of librarians, issuing policy regulations and forming a Synergy Team, holding stakeholder meetings, Launcing Ipustaka Jambi, and carrying out activities advocacy Peer Learning Meeting. The obstacles faced by the Jambi Province Regional Library and Archives Office in developing social inclusionbased libraries are limited budget funds and networks. As for the efforts made by the Regional Library and Archives Office of Jambi province in overcoming the constraints of developing social inclusion-based libraries, namely establishing cooperation with various parties, both from the province, district and private sector and utilizing the existing budget optimally.

Conclusions. Based on the research that has been done on the DPAD strategy in developing a social inclusion-based library. With this strategy, it is hoped that this social inclusion program can run well and can be developed for program development in program recipient libraries, namely district libraries and village libraries.
\end{abstract}

Keyword: Strategi, Inklusi Sosial, Perpustakaan Umum, Masyarakat Literate 


\begin{abstract}
ABSTRAK
Pendahuluan. Tujuan dari penelitian ini adalah untuk mengetahui Strategi DPAD Provinsi Jambi dalam mengembangkan Perpustakaan Berbasis Inklusi Sosial untuk Mewujudkan Masyarakat Literat, faktor-faktor kendala dalam pengembangan perpustakaan berbasis inklusi sosial dalam upaya 2 mewujudkan masyarakat literat di Dinas Perpustakaan dan Arsip Daerah Provinsi Jambi, dan upaya yang dilakukan untuk mengatasi kendala tersebut.

Metode Penelitian. Penelitian ini menggunakan metode kualitatif deskriptif dengan pendekatan purposive sampling.

Hasil Pembahasan. Hasil penelitian ini menunjukkan bahwa terdapat beberapa strategi yang dilakukan DPAD Provinsi Jambi dalam mengembangkan inklusi sosial di perpustakaan yaitu: melibatkan Peran Aktif Pustakawan, Mengeluarkan regulasi kebijakan dan pembentukan Tim Sinergi, Melakukan pertemuan pemangku kepentingan (Stakeholder Meeting), Launcing Ipustaka Jambi, dan melakukan kegiatan advokasi Peer Learning Meeting. Kendala- kendala yang dihadapi Dinas Perpustakaan dan Arsip Daerah Provinsi Jambi dalam pengembangan perpustakaan berbasis inklusi sosial adalah keterbatasan anggaran dana dan jaringan. Adapun upaya yang dilakukan Dinas Perpustakaan dan Arsip Daerah provinsi Jambi dalam mengatasi kendala pengembangan perpustakaan berbasis inklusi sosial yaitu menjalin kerjasama dengan berbagai pihak baik dari provinsi, kabupaten maupun swasta serta memanfaatkan anggaran yang ada secara optimal.

Kesimpulan dan Saran. Berdasarkan penelitian yang yang telah dilakukan terhadap strategi DPAD dalam mengembangkan Perpustakaan berbasis inklusi sosial. Dengan adanya strategi tersebut diharapkan agar progam inklusi sosial ini dapat berjalan dengan baik dan bisa dikembangkan untuk pengembangan program pada perpustakaan penerima program yaitu perpustakaan kabupaten dan perpustakaan desa.
\end{abstract}

Kata Kunci: Strategi, Inklusi Sosial, Perpustakaan Umum, Masyarakat Literate

\title{
A. PENDAHULUAN
}

Perpustakaan memiliki peran yang begitu penting dalam penyebaran informasi hal ini dikarenakan didalam sebuah perpustakaan terdapat banyak sekali buku dan disetiap bukunya itu memiliki beragam informasi yang sangat berguna bagi pembacanya. Karena dianggap sebagai sumber informasi maka perpustakaan juga sangat berperan dalam menciptakan masyarakat yang literat, yaitu 
masyarakat yang literat akan informasi. ${ }^{1}$ Perpustakaan diharapkan tidak hanya sebagai tempat membaca berbagai jenis buku, namun mampu menjadikan masyarakat sebagai penumbuh dan pegiat literasi yang akhirnya akan meningkatkan kesejahteraan masyarakat. Secara sederhana, literasi dapat diartikan sebagai sebuah kemampuan membaca dan menulis.

Literasi informasi atau melek informasi merupakan kemampuan untuk menemukan, mengevaluasi, dan menggunakan informasi yang dibutuhkan secara efektif, untuk memenuhi kebutuhan pemustaka akan informaisi yang dibutuhkan. ${ }^{2}$ Dengan timbulnya kesadaran literasi informasi pada masyarakat diharapkan dapat meningkatkan kualitas pereknomian dengan bermunculannya lapangan usaha. Penyediaan bukubuku yang sesuai dengan lapangan pekerjaan masyarakat akan merangsang pembelajaran sepanjang hayat bagi masyarakat yang ingin berkembang bersaing dalam dunia usaha. ${ }^{3}$

Sejalan dengan hal tersebut, pemerintah Indonesia secara serius melalui Badan Perencanaan Pembangunan Nasional (Bappenas) dan Perpustakaan Nasional RI telah menetapkan program ini serta menjadikan perpustakaan sebagai salah satu program prioritas nasional percepatan pengentasan kemiskinan di Indonesia. Hal ini didasari oleh perpustakaan yang dianggap mampu menjadi wadah peningkatan kesejahteraan masyarakat melalui tersedianya akses informasi dari buku dan internet yang dimiliki oleh perpustakaan, tersedianya ruang belajar dan berkegiatan masyarakat, sertaadanya pendampingan yang diberikan oleh pustakawan, sehingga, mampu mendorong terciptanya masyarakat yang lebih sejahtera. ${ }^{4}$

${ }^{1}$ Riska Darmayanti, Membangun Budaya Literasi Informasi Bagi Masyarakat Kampus ( Jurnal Iqra' Vol 10 No.01 Mei 2016), hal. 92

${ }^{2}$ Purnomo, Peranan Perpustakaan Umum dalam Gerakan Literasi Informasi Sebagai Sarana Pembelajaran Sepanjang Hayat, hal. 5

${ }^{3}$ Purnomo, Peranan Perpustakaan Umum dalam Gerakan Literasi Informasi Sebagai Sarana Pembelajaran Sepanjang Hayat, hal. 9

${ }^{4}$ Rani Auliawati Rahman, Strategi Sukses Transformasi Perpustakaan Desa Berbasis Inklusi Sosial untuk Masyarakat Sejahtera Studi Pada Perpustakaan Desa Gampingan Membaca Malang), hal. 908 
Pada tahun 2018 terdapat 21 provinsi yang mendapat bantuan dari transformasi perpustakaan berbasis inklusi sosial, salah satunya Provinsi Jambi, meliputi 4 kabupaten dan 20 desa diantaranya kabupaten Batanghari, Kabupaten Bungo, Kabupaten Tanjung Jabung Barat, dan Sarolangun. Program transformasi perpustakaan berbasis inklusi sosial ini ditujukan kepada perpustakaan umum provinsi, kabupaten/kota yang memiliki komitmen tinggi untuk mengembangkan perpustakaan berbasis inklusi sosial di daerahnya. Transformasi perpustakaan berbasis inklusi sosial tidak hanya untuk mempertahakankan eksistensi suatu perpustakaan saja, akan tetapi juga merupakan salah satu bentuk dukungan yang dilakukan oleh perpustakaan untuk mendukung program pembangunan berkelanjutan atau Sustainable Development Goals (SDG's).

Sebagaimana seruan dari IFLA yang meminta kepada semua pihak untuk menjadikan perpustakaan di setiap bagian dunia menjadi mitra dalam rencana pembangunan nasional dan daerah di setiap negara serta mendorong agar perpustakaan masuk dalam rencana pembangunan nasional untuk SDGs. Adanya seruan dari IFLA diatas menjadikan perpustakaan memegang peranan penting untuk berperan dalam meningkatkan kesejahteraan masyarakat melalui ketersedian akses layanan informasi, sebagai pusat belajar dan berkegiatan masyarakat. ${ }^{5}$ Hasil penelitian ini diharapkan menjadi sumbangan khususnya bagi ilmu perpustakaan, sehingga dapat memperluas dan memperkaya khazanah keilmuan.

\section{B. TINJAUAN PUSTAKA}

\section{Pengertian Strategi}

Menurut Lawrence dalam Amri Hariri, menyatakan bahwa strategi merupakan rencana yang disatukan, menyeluruh dan terpadu yang mengaitkan

\footnotetext{
${ }^{5}$ Rani Auliawati Rahman, Strategi Sukses Transformasi Perpustakaan Desa Berbasis Inklusi Sosial untuk Masyarakat Sejahtera Studi Pada Perpustakaan Desa Gampingan Membaca Malang), hal. 907
} 
keunggulan strategi perusahaan dengan tantangan lingkungan dan yang dirancang untuk memastikan bahwa tujuan utama perusahaan dengan tantangan lingkungan dan yang dirancang untuk memastikan bahwa tujuan utama perusahaan dapat dicapai melalui pelaksanaan yang tepat oleh perusahaan. Sedangkan menurut Amstrong dalam Amri yang mengatakan bahwa strategi dapat didefinisikan sebagai penentuan dari tujuan jangka Panjang dan sasaran sebuah perusahaan, dan penerimaan dari serangkaian Tindakan serta alokasi dari sumber-sumber yang dibutuhkan untuk melaksanakan tujuan tersebut. Sedangkan menurut Chandler dalam Robbins, mendefinisikan strategi sebagai penetapan tujuan jangka panjang dan sasaran perusahaan, dan penerapan serangkaian Tindakan serta alokasi sumber daya yang penting untuk melaksanakan sasaran. Serta menuurut Child, strategi adalah sekumpulan pilihan dasar atau kritis mengenai tujuan dan cara bisnis. ${ }^{6}$

Strategi merupakan alat yang digunakan untuk mencapai tujuan, dalam pengembangannya konsep mengenai strategi harus terus memiliki perkembangan dan setiap orang mempunyai pendapat atau definisi yang berbeda mengenai strategi. Strategi adalah sarana bersama dengan tujuan jangka panjang yang hendak dicapai. Strategi adalah rencana berkala besar, dengan orientasi masa depan, guna berinteraksi dengan kondisi persaingan untuk mencapai tujuan. ${ }^{7}$

\section{Pengertian Perpustakaan}

Menurut Encyclopedia Britannica dalam Abdurahman, sebuah perpustakaan (dari kata liber book) adalah himpunan bahan-bahan tertulis atau tercetak yang diatur dan diorganisasikan untuk tujuan studi dan penelitian atau pembacaan umum atau kedua-duanya, sedangkan menurut Kamus Istilah

\footnotetext{
${ }^{6}$ Amri Hariri. Strategi Personal Branding Pustakawan Di Perpustakaan Universitas Muhammadiyah Purwokerto. Prosiding. Surabaya: Universitas Surabaya, 2018. Hal. 175-177

${ }^{7}$ Hartati Mega, Nur and Achmad Kuncoro, Analisis Strategi Bisnis Pada PT Abadi Samudera Indonesia (Undergraduate Thesis, Binus, 2014), hal. 9
} 
Perpustakaan dan Dokumentasi yang diterbitkan oleh Pusat Pembinaan dan Pengembangan Bahasa, perpustakaan diartikan sebagai (1) koleksi buku, majalah, dan bahan kepustakaan lainnya yang disimpan untuk dibaca, dipelajari, dan dibicarakan; (2) tempat, gedung, atau ruangan yang disediakan untuk pemeliharaan dan penggunaan koleksi buku. ${ }^{8}$ Perpustakaan adalah sebuah ruangan, bagian sebuah gedung, ataupun gedung itu sendiri yang digunakan untuk menyimpan buku dan terbitan lainnya yang biasa disimpan menurut tata susunan tertentu untuk digunakan pembaca, bukan untuk dijual. Atau suatu unit kerja yang subtansinya merupakan sumber informasi yang setiap saat dapat digunakan oleh pengguna jasa layanan. ${ }^{9}$

\section{Pengertian Inklusi Sosial}

Inklusi sosial adalah upaya menempatkan martabat dan kemandirian individu sebagai modal utama untuk mencapai kualitas hidup yang ideal. Melalui inklusi sosial, Program peduli mendorong agar seluruh elemen masyarakat mendapat perlakuan yang setara dan memperoleh kesempatan yang sama sebagai warga negara, terlepas dari perbedaan apapun. Inklusi sosial adalah sebuah pendekatan untuk membangun dan mengembaangkan sebuah lingkungan yang semakin terbuka, mengajak masuk dan mengikutsertakan semua orang dengan berbagai perbedaan. ${ }^{10}$

Inklusi sosial digunakan sebagai sebuah pendekatan untuk membangun dan mengembangkan sebuah lingkungan yang semakin terbuka, mengajak masuk dan mengikutsertakan semua orang dengan berbagai perbedaan latar belakang, karakteristik, kemampuan, status, kondisi, etnik, budaya dan lainnya. Lingkungan inklusi adalah lingkungan sosial masyarakat yang terbuka, ramah, 
meniadakan hambatan dan menyenangkan karena setiap warga masyarakat tanpa terkecuali saling menghargai dan merangkul setiap perbedaan. ${ }^{11}$

Konsep inkluisi sosial ini membangun suatu masyarakat tanpa pandang bulu, dan agar masyarakat semakin terbuka melalui peningkatan partisipasi serta peluang, akses ke sumber daya dan rasa saling menghormati. ${ }^{12}$ Konsep inklusi sosial pertama kali muncul pada tahun 1970- an di prancis sebagai respon terhadap krisis kesejahteraan di negara-negara eropa, yang memiliki dampak yang meningkat pada kerugian sosial di eropa. Konsep ini menyebar ke seluruh eropa dan inggris sepanjang tahun 1980-an dan 90-an. ${ }^{13}$

\section{Inkluisi Sosial di Perpustakaan}

Inklusi sosial di bidang perpustakaan mulai diwacanakan pada tahun 1999 melalui dokumen Libraries for All: Social Inclusion in Public Libraries Policy Guidance for Local Authorities in England October 1999. kunci dalam pengembangan inklusi sosial di bidang perpustakaan, yaitu:

a. Inklusi sosial di perpustakaan umum, Perpustakaan umum adalah titik fokus untuk penyediaan layanan informasi di masyarakat, sehingga mereka memiliki peran penting untuk dimainkan dalam membantu mengembangkan inklusi sosial sebagai perwujudan dari belajar sepanjang hayat.

b. Kontek inklusi sosial, Pada saat yang sama masalah individu sering terkait dengan masalah lokalitas juga keadaan pribadi. Namun proyek pengembangan masyarakat di Inggris dan di tempat lain telah menunjukkan bahwa kebijakan yang berhasil untuk inklusi sosial harus mendorong orang untuk mengambil tindakan bersama pada masalah yang

${ }^{11}$ Thamrin Husni, Proses Inklusi Sosial Anak Jalanan Dampingan Kelompok Kerja Sosial Perkotaan KKSP, Hal. 15

${ }^{12}$ Reza Mahdi dan Andi Asari. Pemberdayaan Masyarakat oleh Perpustakaan Umum Kabupaten Magelang dalam Mewujudkan Layanan Perpustakaan Berbasis Inklusi Sosial. Jurnal PKS Volume 19 Nomor 3 Desember 2020

${ }^{13}$ Suharyanto Malawa, Model dan Konsep Transpormasi Perpustakaan Berbasis Inklusi Sosial di Era Digital, (Konferensi Perpustakaan Digital Indonesia. 2019 ), hal. 2 
mempengaruhi lingkungan mereka. Yang menjadi konteks dalam inklusi sosial ini adalah keterlibatan masyarakat dalam pembaharuan lingkungan.

c. Identifikasi dan hambatan keterlibatan masyarakat,

d. Kebijakan inklusi sosial, Inklusi sosial harus diarusutamakan sebagai prioritas kebijakan untuk perpustakaan dan layanan informasi. Pengarusutamaan berarti menempatkan prinsip di jantung pembuatan kebijakan atau pengembangan layanan. Masalah inklusi sosial harus mendukung semua aspek penyediaan perpustakaan. Ini berlaku di manalayanan ditingkatkan, dan ketika ada tekanan untuk mengurangi layanan perpustakaan. Perpustakaan umum dan layanan informasi harus tersedia dan dapat diakses oleh semua orang. Untuk membantu mewujudkan tujuan ini, perpustakaan harus memberikan layanan kepada kelompok warga tertentu, seperti orang lanjut usia dan orang cacat, untuk membantu mereka mengatasi pengucilan mereka dan memungkinkan mereka untuk lebih aktif dan terinformasi. Perpustakaan umum menggunakan layanan perpustakaan keliling sehingga memudahkan masyarakat untuk mendapatkan koleksi yang dibutuhkannya.

\section{Masyarakat Literate}

Seseorang dikatakan literate apabila orang tersebut sudah mampu memahami sesuatu disebabkan oleh orang tersebut membaca informasi yang tepat dan melakukan sesuatu berdasarkan pemahamannya terhadap isi bacaan tersebut. ${ }^{14}$ Literasi informasi merupakan suatu keterampilan yang sangat penting untuk dikuasai, terutama di era globalisasi saat ini. Orang yang melek informasi adalah orang yang mampu menyadari kapan informasi diperlukan dan bahkan juga mempunyai kemampuan untuk menemukan, mengevaluasi, dan menggunakan informasi tersebut secara efektif. Literasi informasi juga

${ }^{14}$ Jaka Warsihna, Meningkatkan Literasi Membaca dan Menulis dengan Teknologi Informasi dan Komunikasi, (Jurnal Kwangsan, Vol. 4 No. 2, Edisi Desember 2016), hal. 68 
merupakan prasyarat dalam masyarakat informasi dan merupakan hak azazi manusia untuk belajar sepanjang hayat. ${ }^{15}$

\section{METODOLOGI PENELITIAN}

Penelitian ini dilakukan di lingkungan Dinas Perpustakaan dan Arsip Daerah Provinsi Jambi Tahun 2020. Metode Penelitian yang digunakan dalam penelitian ini adalah kualitatif dengan menggunakan Pendekatan deskriptif. Data dikumpulkan melalui metode pengumpulan data observasi, wawancara dan dokumentasi. Teknik pengambilan sampel dengan menggunakan "Purposive Sampling" yaitu teknik pengambilan sampel sumber data dengan pertimbangan tertentu, misalnya orang tersebut paling tahu tentang apa yang diharapkan Adapun yang menjadi objek penelitiannya yaitu Dinas Perpustakaan dan Arsip Daerah Provinsi Jambi yang beralamat di jalan Rd Poerboyo Kolopaking no 56 Telanai Pura Jambi Karena penelitian ini berbentuk kualitatif maka data primer diperoleh dengan cara wawancara dan observasi. Dalam hal ini peneliti mencari dan mengumpulkan data yang berkenaan langsung berkaitan dengan pokok permasalahan dalam penelitian ini. Subjek dalam penelitian ini adalah Kepala bidang 12 Jaka Warsihna, Meningkatkan Literasi Membaca dan Menulis dengan Teknologi Informasi dan Komunikasi, (Jurnal Kwangsan, Vol. 4 No. 2, Edisi Desember 2016), hal. 6813 Atikah Syamsi, Penguatan Literasi Informasi Berbasis Perpustakaan Bagi Peningkatan Mutu Akademik Mahasiswa PGMI IAIN Cirebon (Jurnal Pendidikan Sekolah Dasar Vol.2, No. 2 Agustus 2016), hal. 277 pembinaan, pengembangan perpustakaan dan pembudayaan kegemaran membaca, Kepala Dinas perpustakaan dan arsip daerah provinsi Jambi serta pustakawan Dinas perpustakaan dan arsip daerah provinsi jambi yang telah direkomendasikan.

${ }^{15}$ Atikah Syamsi, Penguatan Literasi Informasi Berbasis Perpustakaan Bagi Peningkatan Mutu Akademik Mahasiswa PGMI IAIN Cirebon (Jurnal Pendidikan Sekolah Dasar Vol.2, No. 2 Agustus 2016), hal. 27 


\section{HASIL DAN PEMBAHASAN}

\section{Strategi Pengembangan Perpustakaan Berbasis Inklusi Sosial di Dinas} Perpustakaan dan Arsip Daerah Provinsi Jambi

a. Peran Aktif Pustakawan

Pustakawan adalah salah satu profesi yang dapat mempengaruhi masa depan bangsa. Pustakawan bertugas untuk membimbing dan mengajarkan pemustaka dalam hal mencari bahan bacaan yang sedang dibutuhkan, termasuk membimbing pemustaka agar bisa lebih baik dalam memilih buku. Bahkan juga bukan hanya untuk mendapatkan buku yang dibutuhkan tetapi untuk memperoleh subyek lain yang ada korelasi buku dengan buku yang dibutuhkan.

b. Mengeluarkan Regulasi Kebijakan Dan Pembentukan Tim Sinergi

Regulasi kebijakan merupakan instrumen penting dalam pembentukan, penyelenggaraan,pengelolaan serta pengembangan perpustakaan. Pengembangan perpustakaan harus mencapai berbagai aspek perpustakaan, baik teknis dalam penyelenggaraan perpustakaan maupun regulasi perpustakaan itu sendiri. Tujuandibuatnya regulasi kebijakan tentang transformasi perpustakaan berbasis inklusi sosial yaitu untuk memperjelas program transformasi perpustakaan berbasis inklusi sosial. Dinas Perpustakaan dan Arsip Daerah Provinsi Jambi mengeluarkan Regulasi Kebijakan berupa SK Gubernur tentang tim sinergi transformasi perpustakaan berbasis inklusi sosial.

c. Pertemuan Pemangku Kepentingan (Stakeholder Meeting)

Stakeholder Meeting transformasi perpustakaan berbasis inklusi sosial ini merupakan kegiatan mempertemukan para stakeholder baik di tingkat provinsi, kabupaten dan pihak swasta lainnya dengan misi literasi untuk kesejahteraan masyarakat. Tujuan dari pelaksanaan Stakeholder Meeting ini adalah untuk membangun kesadaran tentang pentingnya pengembangan perpustakaan untuk meningkatkan kualitas hidup masyarakat. Selain itu 
untuk membangun dukungan dan komitmen dari Stakeholder untuk pengembangan perpustakaan berbasis inklusi sosial, Juga untuk menyusun rencana sinergi yang berkelanjutan antar stakeholder untuk mendukung pengembangan berkelanjutan. Kegiatan ini dilakukan untuk mencari dukungan atau sponsor dari para stakeholder.

d. Melaunching Aplikasi IPustaka Jambi

IPustaka Jambi diluncurkan untuk memenuhi kebutuhan informasi masyarakat Jambi tanpa harus datang ke perpustakaan. Untuk dapat mengakses dan menggunakan Ipustaka Jambi secara utuh maka pemustaka harus mendaftar terlebih dahulu. Pendaftaran tidak mengharuskan atau dilakukan verifikasi tertentu, sehingga masyarakat yang tidak memiliki KTP Jambi pun tetap bisa mengakses ipustaka Jambi. Keuntungan menjadi anggota iPuataka Jambi antara lain dapat meminjam koleksi yang ada di aplikasi Ipustaka Jambi. Peminjaman buku melalui Ipustaka dilakukan secara mandiri dan automatis melalui menu collection. Anggota bisa meminjam buku maksimal 2 judul dalam satu waktu, dengan durasi peminjaman selama 1 minggu. Setelah 1 minggu maka secara otomatis buku yang kita pinjam tidak dapat diakses, kecuali kita meminjamnya kembali. Mengembangkan layanan perpustakaan berbasis online melalui aplikasi sebenarnya jika dipandang dari sisi ekonomis juga lebih menguntungkan. Biaya pengembangan aplikasi memang membutuhkan dana besar namun jika dipandang dari sudut investasi akan menjadi lebih murah, karena biaya tersebut hanya dikeluarkan besar ketika awal. Sedangkan untuk operasional jauh lebih murah dari biaya pengembangannya.

\section{e. Pelaksanaan Peer Learning Meeting}

Pelaksanaan Peer Learning Meeting ini bertujuan untuk memfasilitasi proses saling belajar dan berbagi pengalaman antar perpustakaan. Serta memotivasi danmembangun kepercayaan diri peserta untuk terus melaksanakan rencana 
kerja transformasi perpustakaan kabupaten maupun desa, memperkuat proses mentoring dan minitoring perpustakaan.

\section{Kendala Pengembangan Perpustakaan Berbasis Inklusi Sosial Dalam} Upaya Mewujudkan Masyarakat Literet di Dinas Perpustakaaan dan Arsip Daerah Provinsi Jambi

a. Keterbatasan anggaran dana Anggaran dana merupakan sebuah hal yang perlu disiapkan dalam sebuah organisasi atau institusi agar dapat menampung kegiatan-kegiatan yang akan dilaksnakan. Perpustakaan merupakan lembaga yang tumbuh dan berkembang baik dalam arti koleksi, jasa maupun manusianya. Setiap perpustakaan tentunya memerlukan anggaran yang besar untuk membiayai semua keperluan operasional, staf serta penambahan koleksi perpustakaan.

b. Jaringan Sebelum menjalankan program transformasi perpustakaan berbasis inklusi sosial para pihat terkait harus berkomitmen untuk menyediakan jaringan internet, hal ini dilakukan untuk mempermudah pihak yang terkait melaporkan kegiatan nya secara online kepada Perpustakaan Nasional.

\section{Upaya yang dilakukan Dinas Perpustakaan dan Arsip Daerah Provinsi} Jambi dalam mengatasi kendala tersebut.

a. Melakukan Kerjasama Kerjasama pada intinya menunjukkan adanya kesepakatan antara dua orang atau lebih yang saling menguntungkan. Dinas Perpustakaan dan Arsip Daerah Provinsi Jambi menjalin kerja sama dengan Komisi I DPRD Provinsi Jambi. Dinas Perpustkaan dan Arsip Daerah Provinsi Jambi juga melakukan kerjasama dengan berbagai pihak tingkat provinsi, kabupaten dan swasta. Selain itu transformasi perpustakaan berbasis inklusi ini juga melibatkan Komunitas.

b. Memanfaatkan anggaran yang ada secara optimal Anggaran adalah permasalahan yang sampai saat ini selalu menjadi alasan tidak dapat 
berkembangnya sebuah perpustakaan. Dengan adanya program prioritas nasional dan pedoman penyusunan APBD tahun 2020 diharapkan setiap pemerintah daerah provinsi dan kabupaten/kota dapat merencanakan program kegiatan perpustakaan pada tahun 2020 .

\section{E. KESIMPULAN}

Dari hasil uraian diatas dapat ditarik kesimpulan bahwa terdapat beberapa Strategi Pengembangan Perpustakaan Berbasis Inklusi Sosial yang dilakukan Dinas Perpustakaan dan Arsip Daerah Provinsi Jambi dalam Mewujudkan Masyarakat Literet yaitu: melibatkan Peran Aktif Pustakawan, Mengeluarkan regulasi kebijakan dan pembentukan Tim Sinergi, Melakukan pertemuan pemangku kepentingan (Stakeholder Meeting), Launcing Ipustaka Jambi, dan melakukan kegiatan advokasi Peer Learning Meeting. Kendala- kendala yang dihadapi Dinas Perpustakaan dan Arsip Daerah Provinsi Jambi dalam pengembangan perpustakaan berbasis inklusi sosial adalah keterbatasan anggaran dana dan jaringan.Adapun Upaya-upaya yang dilakukan Dinas Perpustakaan dan Arsip Daerah provinsi Jambi dalam mengatasi kendala-kendala pengembangan perpustakaan berbasis inklusi sosial yaitu menjalin kerjasama dengan berbagai pihak baik dari provinsi, 10 kabupaten maupun swasta serta memanfaatkan anggaran yang ada secara optimal. Untuk mengetahui leblh lanjut Peneliti memberikan saran agar peneliti selanjutnya bisa mengkaji lebih jauh lagi pada perpustakaan kabupaten dan perpustakaan desa yang menerima program transformasi perpustakaan berbasis inklusi sosial. 


\section{DAFTAR PUSTAKA}

Auliawati, Rahman, Rani. (2019). "Strategi Sukses Transformasi Perpustakaan Desa Berbasis Inklusi Sosial untuk Masyarakat Sejahtera Studi Pada Perpustakaan Desa Gampingan Membaca Malang",(Seminar Nasional MACOM III Universitas Padjajaran).

Darmayanti, Riska. (2016). “Membangun Budaya Literasi Informasi Bagi Masyarakat Kampus” Jurnal Iqra'. Vol 10 No.01.

Hariri, Amri. 2018. Strategi Personal Branding Pustakawan Di Perpustakaan Universitas Muhammadiyah Purwokerto. Prosiding. Surabaya: Universitas Surabaya,.

Hartono. (2017). "Strategi Pengembangan Perpustakaan Digital Dalam Membangun Aksebilitas Informasi” Jurnal Perpustakaan. Vol.8 No.1.

Husni, Thamrin. (2016) "Proses Inklusi Sosial Anak Jalanan Dampingan Kelompok Kerja Sosial Perkotaan Kksp” (Repositori Institusi Usu)

Libraries For All: "Social Inclusion In Public Libraries Policy Guidance For Local Authorities In England October 1999” (Departemen For Culture, Media And Sport, Gov. Uk)

Purnomo. (2018). "Peranan Perpustakaan Umum Dalam Gerakan Literasi Informasi Sebagai Sarana Pembelajaran Sepanjang Hayat".

Mahdi, Reza dan Andi Asari. 2020. Pemberdayaan Masyarakat oleh Perpustakaan Umum Kabupaten Magelang dalam Mewujudkan Layanan Perpustakaan Berbasis Inklusi Sosial. Jurnal PKS Volume 19 Nomor 3 Desember 2020

Malawa, Suharyanto. (2019). "Model Dan Konsep Transpormasi Perpustakaan Berbasis Inklusi Sosial Di Era Digital”, Konferensi Perpustakaan Digital Indonesia.

Riki Arianto, diakses pada tanggal 7 agustus 2019 dari Https://Dipersip.Riau.Go.Id/Post/Transformasi-Perpustakaan-Berbasis$\underline{\text { InklusiSosial-Dan-Sdgs diakses pada 28Juli2019pukul17.33 }}$ 
Saleh, Abdul Rahman. 2014. Manajemen Perpustakaan. Tangerang Selatan: Universitas Terbuka.

Suwarno, Wiji. (2014) “Dasar-Dasar Ilmu Perpustakaa:Sebuah Pendekatan Praktis”. Jogjakarta: Ar-Ruzz Media

Syamsi, Atikah. (2016). "Penguatan Literasi Informasi Berbasis Perpustakaan Bagi Peningkatan Mutu Akademik Mahasiswa Pgmi Iain Cirebon" Jurnal Pendidikan Sekolah Dasar. Vol.2 No. 2. Warsihna, Jaka. (2016). "Meningkatkan Literasi Membaca Dan Menulis Dengan Teknologi Informasi Dan Komunikasi”, Jurnal Kwangsan. Vol. 4 No. 2. 